hat, so wie sie früher für das gesamte Deutsche Reich von der ehemaligen Reichsanstalt für Wasser- und Lufthygiene in Berlin-Dahlem vertreten worden sind. Mit der Sachbearbeitung ist das Institut für angewandte Zoologie dieser Anstalt in Celle beauftragt worden. Es besteht schließlich Veranlassung zu dem Hinweis, daß dabei dem zweckmäßigen Bestreben nach Würdigung und Auswertung fast 25jähriger amtlicher Erfahrungen der erwähnten früheren Anstalt auch personell zielstrebig Rechnung getragen worden ist und 12jährige größtenteils an der ehemaligen Reichsanstalt in der Schule von den Pionieren J. Wilhelmi und Th. Saling auf diesem Gebiet geleistete eigene Forschungs-, Prüfungsund Gutachtertätigkeit den weiteren Arbeiten zugrunde gelegt werden kann.

\title{
Eigenartiger Rattenschaden
}

\section{Von H. W. Frickhing e r, Irschenhausen/Obb.}

Die Münchener Firma Josef Engel, Institut für Schädlingsbekämpfung, hat mich im vergangenen Frühjahr aufgefordert, zu einer Besichtigung von nicht alltäglichem Rattenschaden im Elefantenstall eines Zirkus mich einzufinden. Dort war der größte Teil der Tiere auf Tournée auswärts und nur 2 Elefanten waren zurückgeblieben. Dadurch war natürlich auch der Futtervorrat sehr zurückgegangen in dem Zirkusgebäude und die dort immer vorkommenden Ratten waren auf schmale Kost gesetzt. In ihrer Nahrungsknappheit hatten sie sich an den Sohlen der schlafenden Elefanten vergriffen! Die Sohlen der Tiere zeigten mehrere Zentimeter tiefe, handtellergroße Flächen, welche die Ratten hineingenagt hatten. Offenbar war dadurch eine Infektion eingetreten. Der eine. der beiden beschädigten Elefanten war stark fiebrig und es bedurfte aller Pflege, um ihn wieder hochzubringen. Die Firma wurde daraufhin beauftragt, die Rattenbekämpfung mit aller Energie durchzuführen, was auch geschah. Nach kurzer Zeit war die .Rattenplage in den Zirkusgebäuden, wie mir die Firma berichtet, durch Auslegen von mit $\mathrm{Mu}$ ritanpaste vergifteten Ködern, ziemlich beseitigt. Der anwesende Wärter erzählte, daß er vor längerer Zeit in Wien ähnliche Schäden bei einem Gastspiel mit einem anderen Zirkus, auch an Elefanten, erlebt hatte, so da13 diese Schädigung an lebenden Elefanten kein Novum, sondern nur eine selten festzustellende Art der Rattenschädigung darstellt.

Wie mir später freundlicherweise Fräulein Erma Mohr, Hamburg, brieflich mitteilte, hat auch schon Carl Hagenbeck in seinem Band „Von Tieren und Menschen." (Berlin 1908) von ähnlichen Schäden auf den Seiten 274 bis 276 geschrieben. Dort heißt es:

„Uber allerlei Erlebnisse bei dem Transport von Elefanten habe ich schon in dem Kapitel über die
Entwicklungszeit des Tierhandels mancherlei erzählt. Hier aber kommt mir noch eine traurige Erinnerung aus dem Jahre 1868 , die so redht zeigt, wie auch in der Tierwelt der Goliath einem David zum Opfer fallen kảnn. Mit einem großen afrikanischen Tiertransport war ich von Triest angekom. men, volle 9 Tage, einschließlich eines zweitägigen Aufenthalts in Wien, hatte die Reise gedauert, Menschen und Tiere waren erschöpft. Es war schon spät abends geworden, als ich alle meine Tiere, unter denen sich auch mehrere junge Elefanten befanden, in den verschiedenen Stallungen untergebracht hatte, und mich endlich nach einer letzten, Inspektion zur Ruhe begeben konnte. Unter den Tieren befand sich alles wohl, wenn auch marode; die Elefanten hatten sich, nachdem sie ihr Futter eingenommen, gleich zum Schlafen niedergelegt. Die armen Tiere hatten im Eisenbahnwagen auf engem Raum gestanden und waren während der Reise wenig zur Ruhe gekommen.

Mitten in der Nacht, es mochte wohl 2 Uhr sein, weckte mich mein alter Wärter mit der Meldung, daß einer der Elefanten röchelnde Töne von sidh gebe und krank zu sein scheine. Idh erschrak und hatte den Willen, sofort nach dem Rechten zu sehen, aber die Müdigkeit überwältigte mich und ich schlief wieder ein. Nach einei Stunde klopfte ein anderer Wärter und brachte eine ganz ähnlich lautende Meldung. Nun war ich nach einigen Minuten in den Ställen, kam aber schon zu spät; ein Elefant war tot, zwei andere lagen im Sterben. Bei der Untersuchung stellte sich heraus, daß die Fußsohlen des verendeten Tieres an drei Stellen durchgefressen waren, das Blut rieselte noch aus den Wunden. "Ratten", sagte mein alter Wärter. Und so war es, die Spuren der scharfen Zähne waren in der Hornhaut deutlich zu erkennen. Die sterbenden Elefanten zeigten die gleichen Verwundungen, die Verblutung war nicht mehr aufzuhalten."

In diesem Falle waren die Schädigungen offenbar viel größer und wohl auch die Tatsache, daß es sich um jüngere Tiere gehandelt hat, die noch nicht in der Gefangenschaft eingewöhnt waren, hat den Tod der verletzten Tiere zur Folge gehabt. 